\title{
A SUCCESSFUL CASE
}

\section{or \\ LUMBAR NEPHRECTOMY FOR RENAL CALCULUS.}

\author{
BY \\ HENRY MORRIS, M.A., F.R.C.S., \\ SURGBON TO, $\triangle$ ND LECTURER ON BURGERY $\triangle T$, THE MIDDLESEX \\ HOSPITAL.
}

(Received May 218t-Read November 25th, 1884.)

REUBEN W-, æt. 35, a labourer, was readmitted into the Middlesex Hospital on the 13th of October, 1883, for the purpose of undergoing an operation for the relief of severe suffering due to renal calculus.

He had been a patient in the hospital on three previous occasions, and an exploratory incision had been made, but had not led to the detection of the calculus.

In May, 1882, he first came under the notice of Dr. Douglas Powell, whose notes of the case were kindly placed at my disposal. The patient at that time was described as a dark-haired, stoutly-built man, complaining of pain in his right side; the pain was not constant, and varied both in severity and position. It was sometimes felt in the epigastrium, at others in the right testicle, thigh, and loin, and shooting down to the bladder. Occasionally it was so severe as to completely "double him 
up." Palpation of the right iliac region gave pain, but steady pressure often gave relief. The urine was 1035, acid, and contained a little blood. His symptoms commenced at the end of 1881 (five months before admission) with cutting pains in the pit of the stomach and right loin, disturbing his rest throughout the night, but more especially towards the morning. He had gradually become worse.

Eleven years ago he had scarlet fever; eight years ago he was disabled for three months by a blow on his head. $\mathrm{He}$ is prone to catch cold, and attributes the onset of his illness to lying in a damp barn. He remained under Dr. Powell's observation for a month, during which time his urine was frequently examined. On the average he voided 40 ounces a day, of specific gravity 1025-1035, acid in reaction, and containing a trace of albumen.

In November, 1882, he was admitted under me, and it was at this time that I explored his kidney through an incision in the loin, both with my fingers and the acupuncture needle. This operation seemed to give him temporary relief, but soon after leaving the hospital in December, 1882, his pains returned worse than ever, and he passed a large quantity of blood with his urine. $\mathrm{He}$ also passed two small stones about the size of pins' heads, but no relief followed.

In May, 1883, he was readmitted, and remained from the 1st to the 31st of this month. At this time pressure over the loin caused pain along the course of the right ureter, and in the right iliac fossa. The urine was 1025, acid, and contained a little blood and pus, and crystals of phosphates. There was nearly always a little pus in it, but blood was less constant and always very limited in amount. Sometimes the urine was perfectly clear, of sp. gr. 1005-1010; at others thick and high coloured, but it was always acid. When clear a much larger quantity was voided.

Jolting movements, such as riding in a cab or railway carriage, and muscular movements, did not increase his 
pain. Paroxysms of very severe pain came on whilst he lay quite quiet, and he was frequently awoke out of sleep by them. It seemed as if any increase of intra-renal tension, or of pressure of the bowel upon the kidney, excited these paroxysms. There was a certain periodicity about their occurrence; 12 midday and 1 a.m. being the times of most severe suffering.

Another exploratory incision, to be followed by nephrectomy if no calculus could be detected, was proposed, but the patient desired to return home first.

On October 13th, 1883, he came back to me worse than ever; a thin, haggard, worn-out looking man, with all the old symptoms aggravated, and having paroxysms of excruciating pain at all hours and under all circumstances. The pain was still all on the right side. His urine had the same characters as before. He had passed another calculus a little larger than a swan shot; its passage caused great suffering, but its escape was not followed by relief. On October 23rd he was in great pain nearly the whole day, and a small calculus, black and facetted, and of the size of a pin's head, was found in the urine.

On October 24th the patient was put under an anæsthetic, and a transverse incision about three inches in length was made in the right loin half an inch above the old cicatrix. Having thoroughly explored the kidney on both surfaces and compressed it all over between my fingers and thumb, and having also punctured it, I failed to detect any stone. The whole kidney was unusually hard, but no one part was harder or more resistant than the rest.

With the assistance of Mr. Gould and the house surgeon, Mr. Thornton, I removed the kidney through theloin wound in the following manner: After completing the separation of the organ from its surroundings I made a vertical incision downwards from the transverse wound, and one inch in front of its hinder end. This was done by cutting from within outwards with a straight probe-pointed knife introduced upon the left index finger. This second incision 
much facilitated the application of the ligatures. In an aneurism needle specially provided with a long handle, a long loop of twisted silk was passed, as I believe, between the ureter and blood-vessels. The silk loop was divided and the vessels tied with one half and the ureter with the other. With the fingers of the left hand I then forcibly dragged upwards the lower ribs, whilst with the right hand I drew the kidney on to the surface of the body. Another ligature was now applied so as to include the whole pedicle. This was tied firmly. The kidney was next cut away with a pair of broad-ended scissors. As the renal pelvis was divided a rounded rough calculus dropped out of the kidney into the wound. The ligatures were all cut off short. During the process of dragging the kidney from its cushion of fat its surface was broken, and for a few moments there was smart hæmorrhage from the laceration. This led me to be as rapid as possible in completing the removal and applying the ligatures, without waiting to attempt to stay the bleeding by pressure. After the kidney was removed a medium-sized vessel in the depth of the wound gave a little trouble, but was at length secured by a pair of Wells' forceps. These forceps were left in for twenty-four hours, and served as an excellent means of drainage in addition to the drain-tube. The edges of the wound were sutured together, a drainage tube was inserted, and terebene oil on lint, and a pad of absorbent cotton wool were retained on the loin by means of a gauze bandage.

It is needless to report in detail the after-progress of the case, as nothing occurred to interrupt recovery.

On the fifth day (October 29th) he complained of pain at the commencement of micturition and continued to do so till November 7th. On the sixth day the stitches were removed. On the seventh day drainage was discontinued. On the tenth day sleeping draughts were no longer needed. On the twelfth day the bowels acted for the first time, and in response to an enema.

On November 22nd the patient sat up for the first time. 


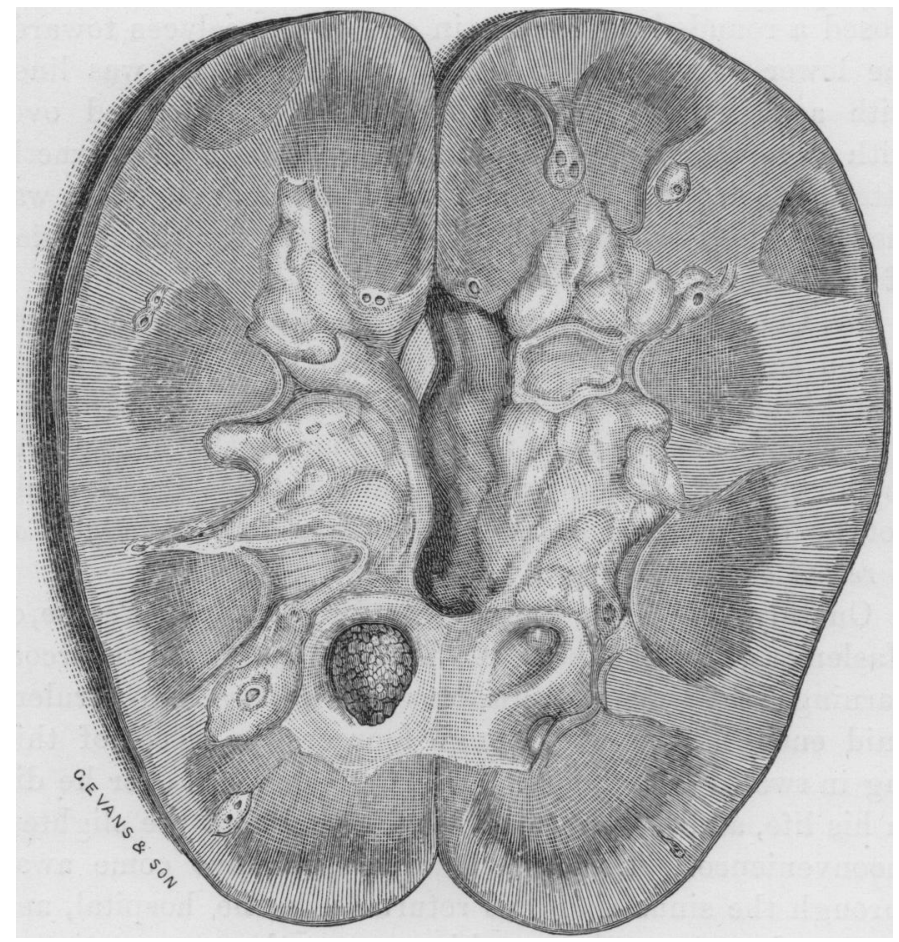

Calculus as seen in situ in the kidney. 
November 29th.-Two decalcified bone drainage-tubes were inserted into long narrow sinuses; the rest of the wound had entirely healed.

December 11th.-He left the hospital in good health, but with one of the sinuses still unhealed.

The examination of the kidney after its removal disclosed a rounded depression in one of the calyces towards the lower end of the organ. This depression was lined with a thin cyst-like membrane and was spotted over with several minute ecchymoses. The calculus exactly fitted into it, and had doubtless there lodged till it was displaced by the manipulations necessary for the excision of the kidney.

Dr. Coupland kindly undertook the microscopical examination and found the kidney structure to be quite healthy. The kidney was of normal size and of great hardness. The calculus as it lay in its depression in the kidney was so thickly surrounded by the renal substance that it could not be detected by pressing the kidney with the fingers as it rested on a table.

On July 28th, 1884, I heard from Dr. Frederick Pearse, of Haslemere, to this effect : " W-is hard at work ' charcoal burning;' the sinus still discharges a watery sero-purulent fluid enough to soak through four or five pieces of thin rag in twenty-four hours. He feels as well as ever he did in his life, and is able to do his work without the slightest inconvenience. Three or four threads have come away through the sinus since his return from the hospital, and he says there is another working out at the present time."

On November 12th, 1884, Dr. Pearse wrote again: "I saw W- a week ago. He is in excellent health and at hard work (charcoal burning). The wound is not quite closed yet; there is still a little watery sero-purulent discharge from it."

Remarks.-This case illustrates the great difficulty which must occasionally be expected in determining the presence of a stone in the kidney by digital exploration and acupuncture. The general symptoms pointed con- 
clusively to renal calculus; but it was an open question whether the disease was in the form of nephrolithiasis, or of one or more distinct calculi of larger size.

The case teaches us not to conclude that a calculus, even of moderate size, is not present, still less that no calculus at all is there, because we cannot discover it either by probing with a needle or by compressing the kidney between the fingers and thumb. It teaches also that the abdominal incision, no more than the lumbar incision, can lead to the detection of a stone when it is thickly surrounded by renal tissue. The position of the stone could not be made out either by the eye or the fingers, when the kidney was out of the body and resting upon a table. It certainly could not have been detected whilst the kidney remained in its fatty cushion in the loin. The prolonged irritation of a calculus in the kidney appears to have had a hardening effect upon the kidney tissue, and in this way to have assisted in completely masking the presence of the calculus.

Two questions arise with respect to the operative treatment of similar cases of calculus in the kidney.

1. Before resorting to nephrectomy can any other step be taken with the view of ascertaining the whereabouts of a stone which has escaped detection by digital examination and needle probing?

2. Is the lumbar, or one of the anterior abdominal incisions, the best for nephro-lithotomy, and for nephrectomy for calculous kidney?

In answer to the first question I would urge that the renal substance should be incised from behind, so as to lay open each of the calyces one after the other until the stone is found. This of course is advised only for cases in which the symptoms are severe and point in a marked manner to calculus in one kidney. Our knowledge of wounds of the kidney gives us assurance that hæmorrhage from such an incision would be easily controlled, that the wound though large would readily cicatrize, and a good working kidney would remain for future service. 
The risks of such an incision are much less than those of nephrectomy, and the patient would have the incalculable advantage of being left with two kidneys instead of one.

In answer to the second question I think the lumbar incision is to be preferred for nephrectomy for calculous kidneys, and that it is the only incision which ought to be employed for nephro-lithotomy.

The arguments which have been advanced in favour of the anterior or abdominal nephrectomy are : $(a)$ when the peritoneal cavity is opened there is more room for the necessary manipulations; $(b)$ that the surgeon can see all that he is doing, and can secure the renal vessels before commencing to enucleate the kidney; $(c)$ that the existence of a second kidney, and its condition, can be ascertained, and the operation abandoned, if only a solitary kidney or a diseased second kidney be discovered ; $(d)$ that the end of the ureter can be brought out of the wound, and that thus the danger of suppuration along the tube can be avoided; (e) that in certain cases, such as hydronephrosis, pyonephrosis, and hydatid and simple cystic enlargements, the peritoneal method, by making evident the nature of the disease, has enabled the surgeon effectually to treat the case by incision and drainage, and thus to do away with the necessity of nephrectomy.

Of these reasons the first two have only an occasional importance, and need not be considered in calculous affections; whilst the others are for the most part purely theoretical, and may sometimes lead to pernicious results.

That an abdominal operation commenced with the intention of nephrectomy, may end advantageously by simply opening and draining the kidney is no more in favour of the incision through the peritoneum than of the lumbar method. In most cases in which such treatment is possible the cystic character of the disease can be diagnosed without any exploratory incision; the cyst can as readily be opened behind the peritoneum as through it; and the margins of the cyst are as easily stitched to the margins 
of the wound in the loin as to those of an incision on the front of the abdomen.

I have thus dealt most satisfactorily through a lumbar incision with the kidney when enormously enlarged by hydronephrosis. The drainage afforded by the dependent position of the loin wound leaves nothing to be desired, and in this respect the lumbar method has a very great advantage over any anterior abdominal procedure.

For the same reason-the advantageous drainage-the divided ureter is best dealt with through the loin. In most cases, particularly of calculous disease, the ureter may safely be left to take care of itself. When fixed to an anterior wound there is an undeniable risk of intestinal obstruction; whereas in lumbar nephrectomy, if suppuration occur about the end of the ureter, either as the effect of its own diseased state or of the ligatures on the renal vessels, the pus can readily escape at the wound, instead of forming an abscess in the abdominal cavity.

Dr. Williston Wright, ${ }^{1}$ in a case reported in the 'New York Medical Journal,' brought the ligatures out at the lower end of an incision along the outer edge of the rectus muscle (Langenbuch's incision); intestinal obstruction resulted, and an abscess which formed about the stump of the renal vessels and ureter failed to empty itself through the operation wound, but fortunately did so through the ureter and bladder.

It seems to me to be anatomically wrong to drag the ureter from the back of the abdomen in order to attach it to the front, thus stretching it across the peritoneal cavity. So that even if it should ever be proved the better practice to open the peritoneum in cases in which an operation could otherwise effect the same end without injuring that structure, I do not think that anything could be urged in favour of this treatment of the ureter.

Respecting the examination of the opposite kidney the argument seems plausible, but practically is almost useless. In the first place there are many cases in which the ' 'New York Med. Journ.,' Feb. 17, 1883. 
nature of the disease, the character of the urine, and the general condition of the patient make clear the diagnosis as to the existence and soundness of the second kidney. In the second place, of what value is a digital examination of a kidney as it lies in the body? Who, holding the kidney enveloped in its capsule and fat in his hand in the post-mortem room, can do more than form an opinion as to its outline and size? Who can thus judge of its structure? Who can say that it is not fatty, granular, lardaceous, tubercular, cancerous, congested, inflamed, suppurating, or the subject of thrombosis? We know the kidney may be irreparably diseased without being enlarged or shrivelled, or without presenting any other character which is recognisable until it is deprived of its capsule or split into halves. So that in spite of a digital examination of the opposite kidney, and even partly because of it, the fatal mistake may be made of performing nephrectomy and leaving behind an organ seriously diseased and utterly insufficient. ${ }^{1}$

If it be true that there are cases in which the normal amount of urea is excreted by the hypertrophied areas of two kidneys, the other areas of which are diseased, the instances of this kind in which nephrectomy will be thought of are infinitely rare; and the pathological condition is not likely to be recognised by an intra-abdominal examination. Where there is a quantity of circumrenal fat it is just possible that even a shrivelled kidney could not be recognised as such. We know a calculus may be undetected.

When there is a large solid tumour, or a painful floating tumour (presumably a floating kidney) to be removed, and owing to some congenital deformity or deficiency, especially of the genital or urinary apparatus, a single kidney is suspected, abdominal nephrectomy should be performed. Therefore, without stating that

1 A case of nephrectomy for scrofulous kidney which gave support to this statement was mentioned in $\mathrm{my}$ reply to the discussion on this paper (see - Proceedings of Royal Medical and Chirurgical Society,' New Series, vol. i, p. 299). 
peritoneal nephrectomy is never the better operation, I venture to assert that the lumbar method is the right one in calculous disease. It is so for these reasons : first, because up to the present time the mortality of the lumbar operation has been only half that of the peritoneal; secondly, the lumbar operation leaves the peritoneal cavity unopened; thirdly, the kidney is of a size to allow its easy removal through the loin, especially if the ilio-costal space be increased, as it ought to be during the operation, by forcibly dragging upwards with the left hand the lower ribs; and fourthly, the loin wound is the most favorable for drainage.

As to nephrolithotomy, I know of no argument which favours the abdominal incision, or the combined abdominal and lumbar incisions in that operation. All that can be ascertained by the anterior incisions, about the organ to be operated upon, can be discovered by the lumbar incision. The incision of the pelvis renalis, or secreting substance, in search of or for extracting a calculus, can only be safely performed behind the uninjured peritoneum ; whereas, the condition of the opposite kidney would not deter one from the operation. On the contrary, if the second kidney is diseased it becomes more urgent not less so to extract the stone, and thereby to place the kidney operated upon in a better state for aiding its fellow, or performing the whole of the excretion.

As all mechanical measures which have been suggested for ascertaining the character of the urine secreted by the opposite kidney have proved to be either impracticable or unreliable, we must depend upon the general symptoms of each case, and upon the estimation of the daily excretion of urea.

In connection with this subject two facts are forced upon the attention by the present case. The first is that we must not infer that the kidneys are diseased because they do not excrete the average daily quantity of urea according to the standard usually given for a healthy adult. 
Persons who have long been living an invalid life, feeding on an invalid diet, taking no exercise and therefore having little or no appetite, and who in consequence of such a life and of suffering and sleeplessness have lost flesh, may have very sound kidneys though they do not excrete more than 250 grains ( $i . e$. not half the standard quantity) of urea in twenty-four hours. An adult under these circumstances with two healthy kidneys may not eliminate more than from $\cdot 8$ to 1.8 per cent. of urea in from 25 to 35 ounces of urine.

Another remarkable fact is the rapidity with which the single kidney increased its power of eliminating urea, though it continued for a long time to discharge a smaller quantity of water than the two kidneys together had done. This is partly to be explained perhaps by the diet. The object was to diminish the nitrogenous matters and fluids as much as possible for the first week or two after the operation. Thus though nearly all the food was taken more or less in a liquid state, there was on the whole less fluid consumed than there would have been under ordinary circumstances. In the week immediately preceding the operation, the daily average quantity of urine passed by this patient was 35 ounces, and the average daily quantity of urea 248 grains.

Five hours after nephrectomy $2 \frac{1}{2}$ ounces of urine of sp. gr. 1022, and containing nearly 11 grains of urea were passed; and three hours later $1 \frac{1}{4}$ ounces of urine of sp. gr. 1040 and containing nearly $5 \frac{1}{2}$ grains of urea. During this time a little iced water and a little milk were the only things swallowed.

In the next five days the average daily quantity of urine was 28 ounces, and of urea $196 \frac{1}{5}$ grains. In the second twenty four hours after the operation the one kidney excreted exactly 196 grains, $i$. e. nearly four fifths of the daily average of the two kidneys just prior to the operation. This was a very sudden rise as compared with the first twenty-four hours after the operation; during this time $59 \frac{1}{2}$ grains of urea were eliminated in 
addition to the $16 \frac{1}{2}$ grains of the evening of the day of operation, which together made a total of 76 grains in the first twenty-four hours.

The quantity of urine in the first twenty-four hours was only $11_{4}^{3}$ ounces; in the next twenty-four hours it was 28 ounces.

Between the seventh and twelfth days inclusive the daily average of urea was 193 grains, and of urine $23 \frac{1}{2}$ ounces-or 55 grains of urea less, and $11 \frac{1}{2}$ ounces of urine less than had been excreted by the two kidneys just previous to the operation.

On and after the third day from the operation the diet consisted of chicken jelly, egg, tea, bread and butter, coffee, milk, and custard.

From the fourteenth day the urea increased considerably. It was very rarely below 200 grains, nearly always above 230 grains, often above 260 grains, occasionally above 320 grains. Even on the fifteenth day $296 \frac{1}{5}$ grains, and on the thirty-sixth day as much as 385 grains were excreted.

On the thirtieth day 45 ounces of urine, containing nearly 276 grains of urea were discharged, but with this single exception the daily quantity of urine did not increase until the sixth week. On the thirty-fifth day and onwards till the patient left the hospital the normal quantity, and occasionally even much more than the normal quantity of urine was passed.

I am indebted to Mr. Paul for the regular and careful examination of the urine over a very prolonged period. The results are of the nature of those derived from a physiological experiment, as the kidney removed was proved to be healthy, and the kidney remaining has proved itself so.

[For discussion on this paper see 'Proceedings of the Royal Medical and Chirurgical Society,' New Series, vol. i, p. 291.]

Postscript.-On August 28th, 1885, Dr. Pearse wrote: “R. Wtold me that a week ago a piece like string came from the wound, which quickly ceased to discharge, and is now healed up."

vOL. LXVIII. 


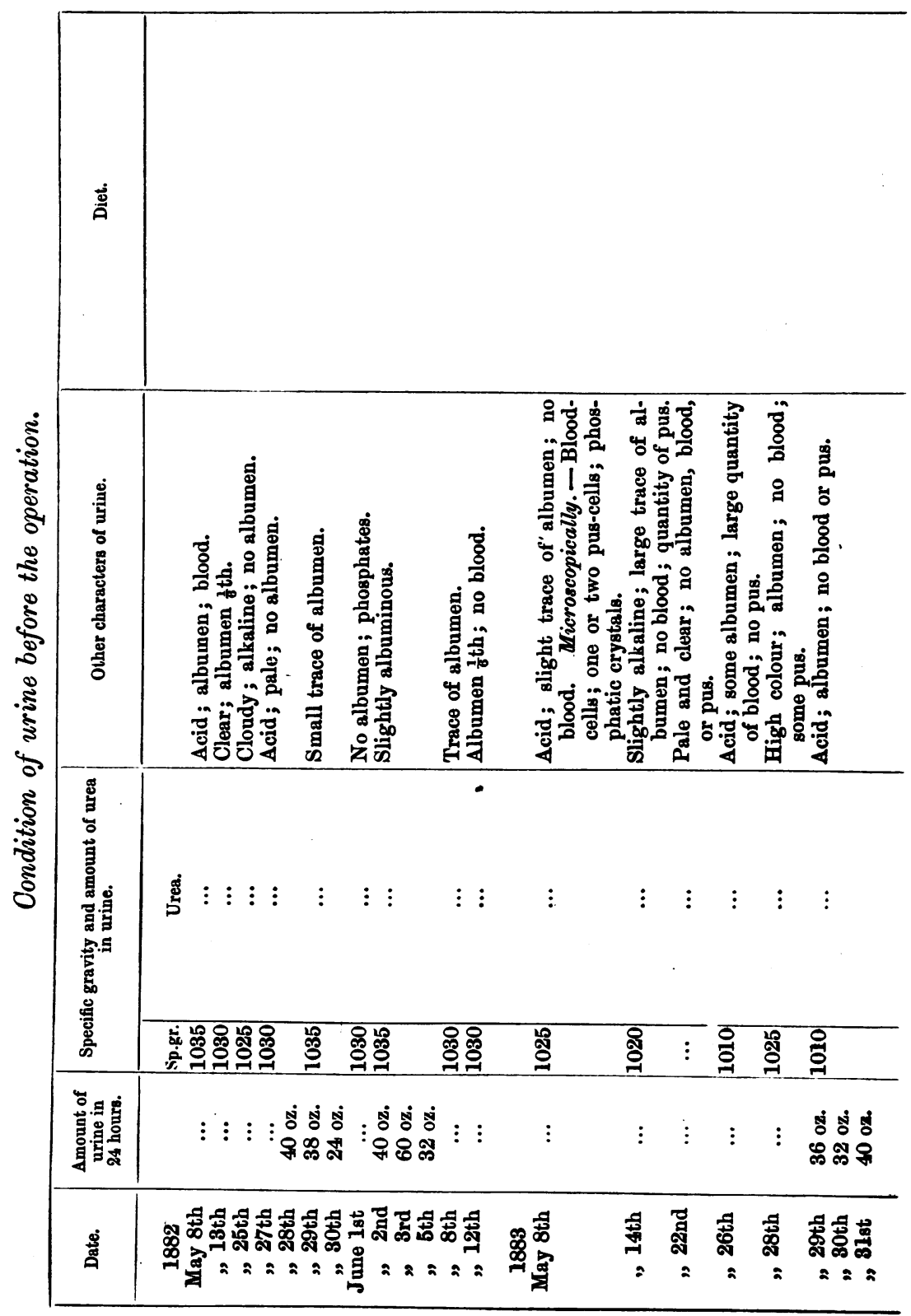




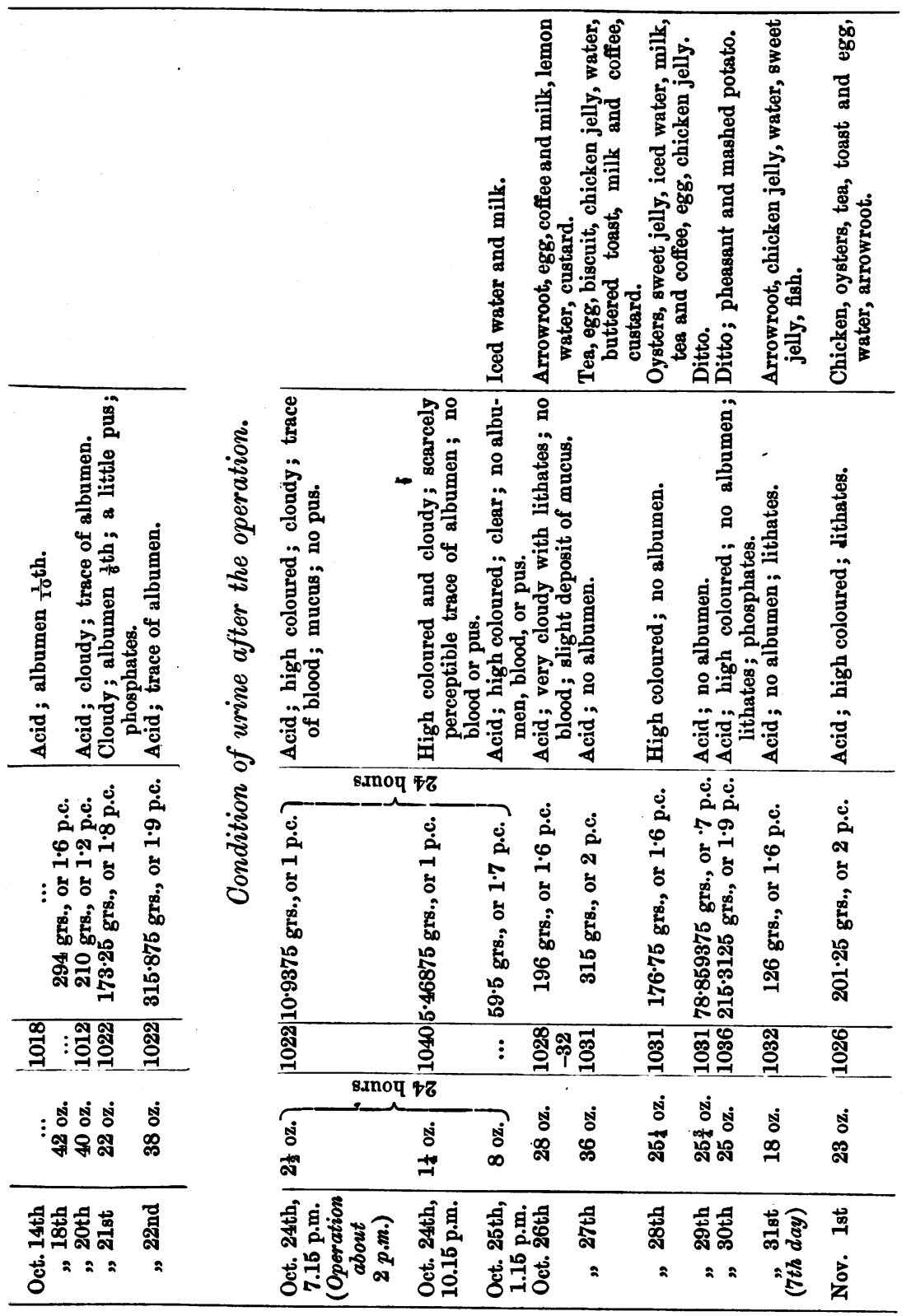




\begin{tabular}{|c|c|c|c|c|c|c|c|c|c|c|}
\hline 芯 & 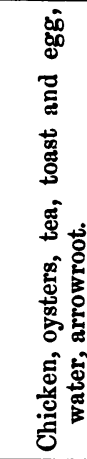 & 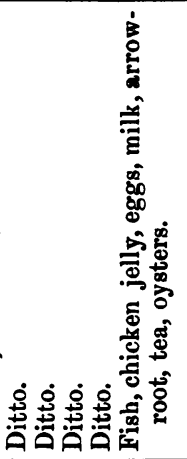 & 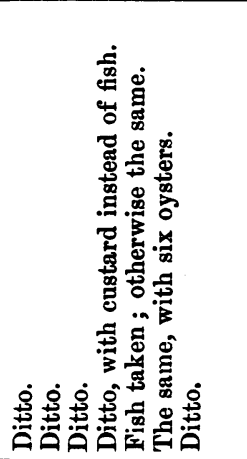 & 密 & 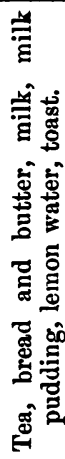 & & 菊 & : & 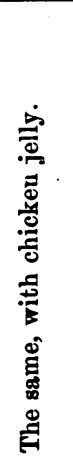 & 离 \\
\hline 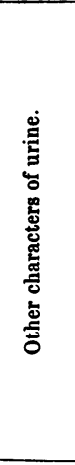 & 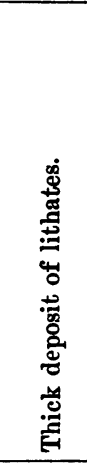 & 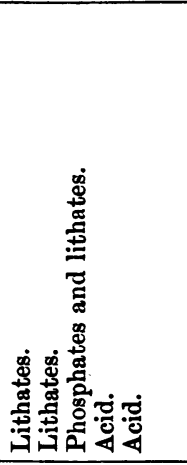 & 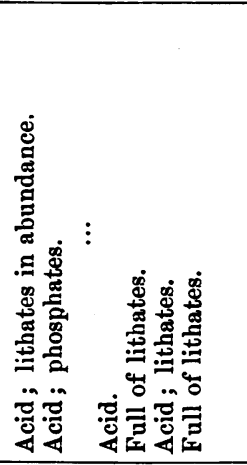 & 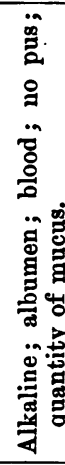 & 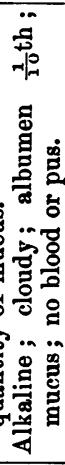 & 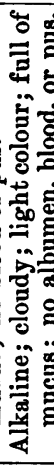 & 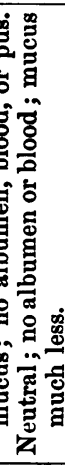 & 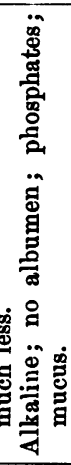 & 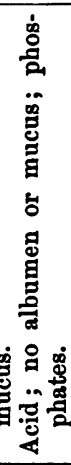 & 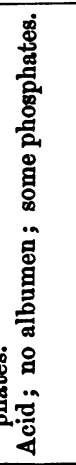 \\
\hline \multirow[t]{2}{*}{ 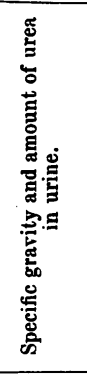 } & 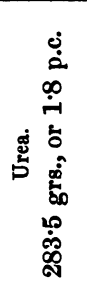 & 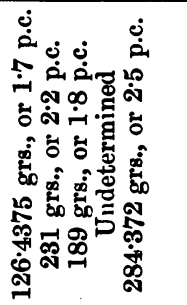 & 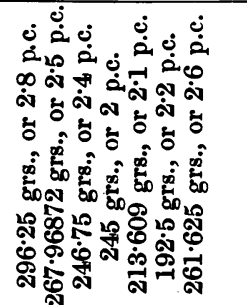 & 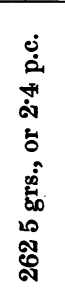 & 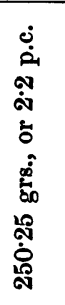 & 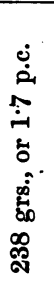 & 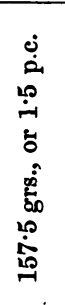 & 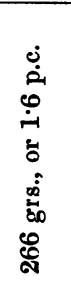 & 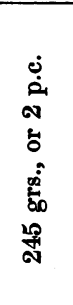 & 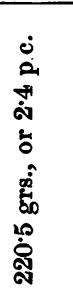 \\
\hline & 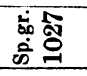 & 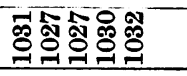 & 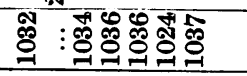 & $\underset{0}{0}$ & 萬 & :ิ & : ํㅡㅁ & : & 今ี & జิ \\
\hline 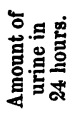 & $\begin{array}{l}\dot{8} \\
\dot{\oplus}\end{array}$ & 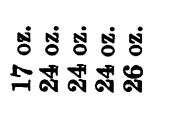 & 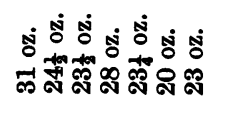 & में & $\begin{array}{l}\text { ¿े } \\
\text { งิ }\end{array}$ & $\begin{array}{l}\text { வें } \\
\text { มิ }\end{array}$ & $\begin{array}{l}\text { \&ें } \\
\text { जี }\end{array}$ & $\begin{array}{l}\dot{0} \\
\infty \\
\infty\end{array}$ & $\begin{array}{l}\dot{1} \\
\text { ๙̊ }\end{array}$ & $\frac{a}{4}$ \\
\hline 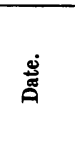 & 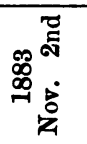 & 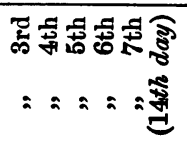 & 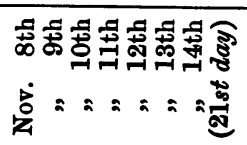 & 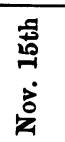 & $\begin{array}{c}\text { 节 } \\
=\end{array}$ & 蛋 & 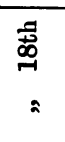 & $\begin{array}{l}\stackrel{े}{\circ} \\
\text { a }\end{array}$ & $\begin{array}{l}\text { 范 } \\
\text { : }\end{array}$ & 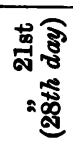 \\
\hline
\end{tabular}




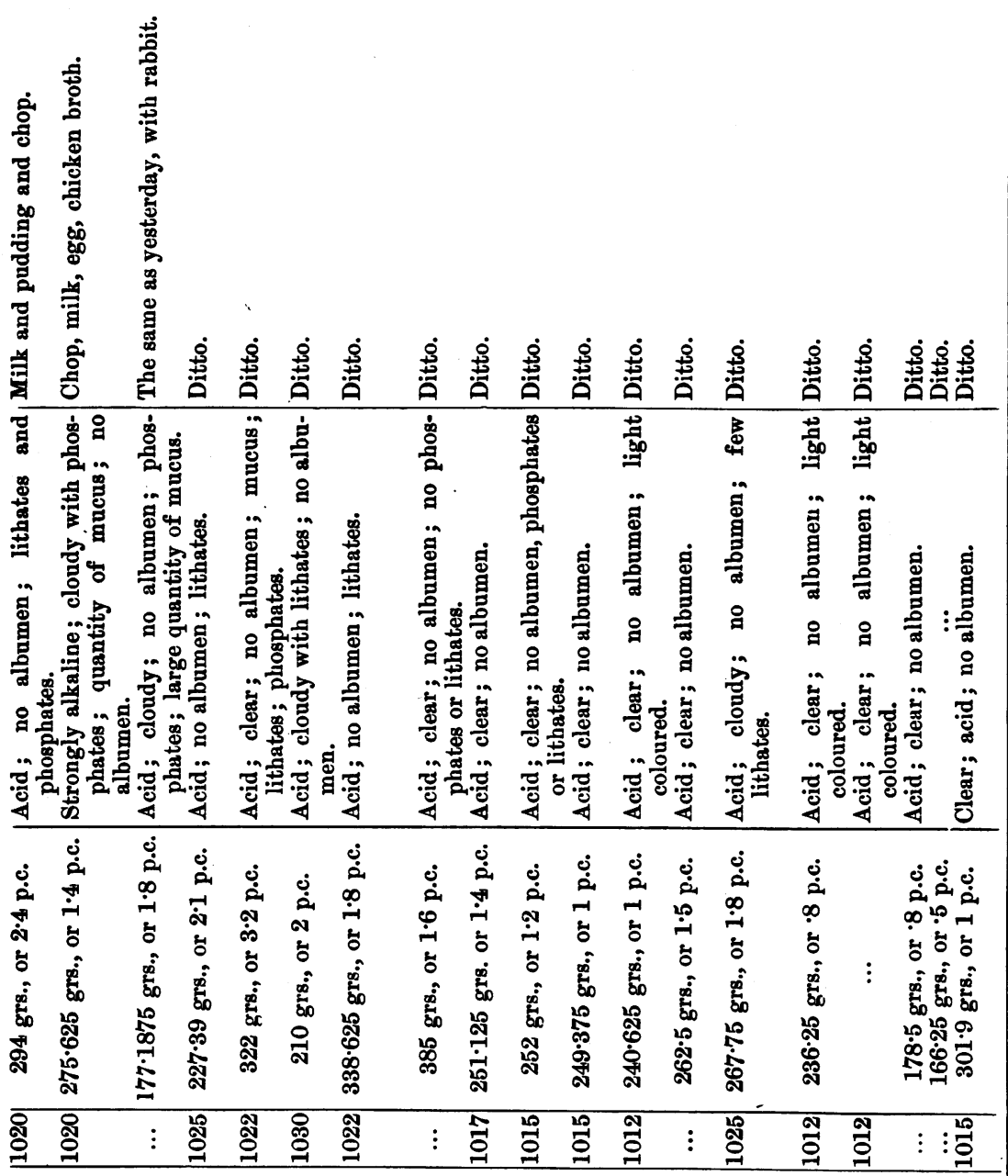

มิ

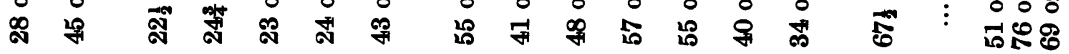

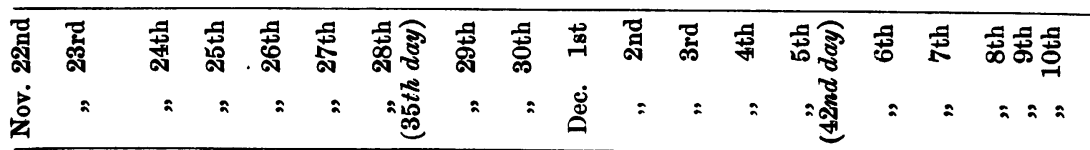

